\title{
New Data on the Foraminifera of the Groundwaters of Middle Asia
}

\author{
by
}

\section{I. MIKHALEVICH*}

At present a number of findings concerning foraminifera, normally typically sea animals, are known from continental waters. A great number of those are located in Middle Asia (Brodsky, 1928, 1929; Schmalhausen, 1950; Rezvoy, 1951; Birstein and Ljovuschkin, 1965; Nikoljuk, 1968; Jankovskaja and Mikhalevich, 1972; Mikhalevich, 1971). Their presence is also reported in wells of the Sahara (Gauthier-Lievre, 1935).

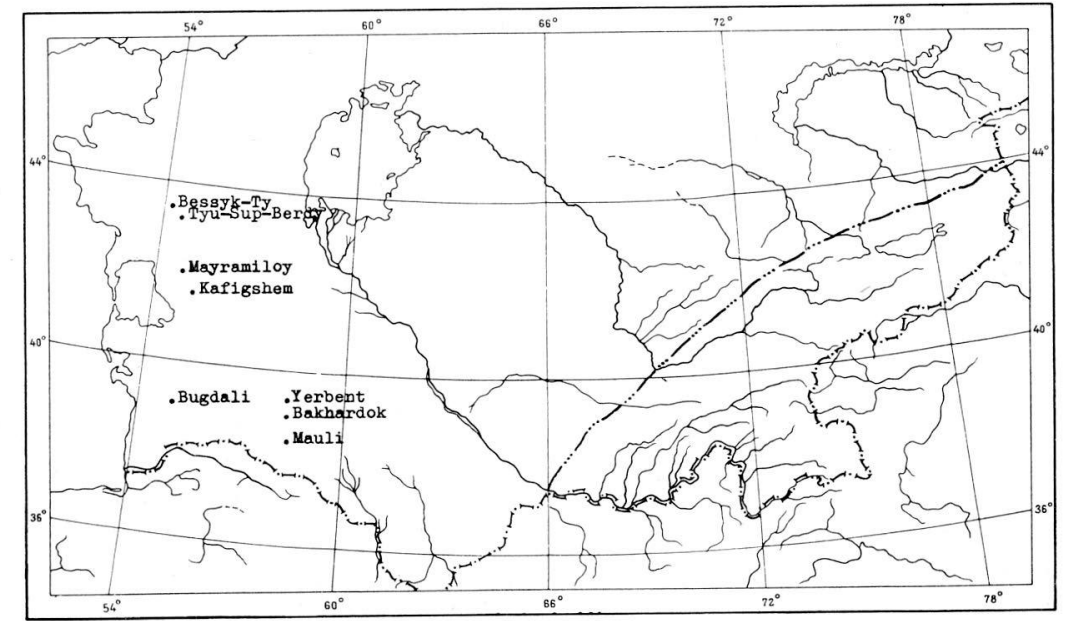

The border between the zone of the bedding of underground waters of heightened salinity and freshened underground waters in the foothills zone.

Map 1. Location of the wells where the foraminifera were found (1973).

* Zoological Institute AN SSSR, Leningrad. 
In the works of Brodsky, Nikoljuk, Jankovskaja and Mikhalevich the inner contents of the shells were investigated by means of different methods and in many cases the presence of the cytoplasmic mass and nucleus was determined.

New data obtained during the expedition to Middle Asia in June-July of 1973 essentially enlarge our knowledge in this field. The samples were taken by means of the bottom-sampler "Ocean" (0.1 sq. m).

Seven new species were discovered in the wells of Kara-Kum and Ust-Urt deserts (map 1). All of them, except Turrilina, differ by extremely small sizes $(0.10-0.27 \mathrm{~mm})$, and thin and fragile walls. For exposing of cytoplasma a water solution of "bengal rose" was used. Stained shells were placed in canada balzam and were observed through transmitted light. All of them are megalosphaeric. Specimens containing the cytoplasma are used for descriptions of new species. In addition, for many of the species described, the empty shells of bigger sizes were located. The presence of young indicated that recent reproduction had taken place.

The types of new species are kept in the collections of the Zoological institute AN SSSR.

Suborder Textulariina Delage et Herouard, 1896. Family Lituolidae de Blainville, 1825. Genus Haplophragmoides Cushman, 1910. Haplophragmoides brodskyi Mikhalevich sp.n. (Fig. 1, 2).
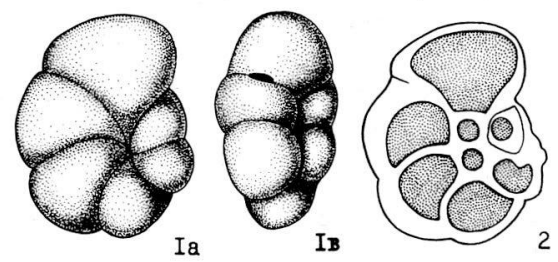

Fig. 1, 2 - Haplophragmoides brodskyi (x75), la, b - the outlook of the test (a - side view, b periferal view), 2 - stained shell in canada balsam.

Test small, oval, much compressed from the lateral sides, with thin, slightly depressed umbilicus; the peripheral margin widely rounded, lobulated; chambers 6 in a whorl, much inflated; sutures thin, deep, nearly straight; wall smooth; aperture an arch opening at the base of the septal face of the last formed chamber. mm.

Holotype - slide N 37(37)-61938, diameter $-0.10 \mathrm{~mm}$, thickness -0.025

Remark. This species differs from $H$. bradyi (Robertson) and $H$. nitidus Goes in having more compressed test and more numeral chambers in a whorl; from $H$. jeffreysii Williamson - with wider peripheral margin, more inflated chambers, with the character of the aperture. The species is named in honour of A. L. Brodsky, the first investigator of the foraminiferal fauna of the underground waters. 
Distribution: the well Bakhardok, at a depth $20 \mathrm{~m}$, on the sand ground, 2 specimens.

Suborder Rotaliina Delage et Herouard, 1896. Family Turrilinidae Cushman, 1927. Genus Turrilina Andreae, 1884. Turrilina turcomanica Mikhalevich sp.n. (fig. 3, 4, 5).
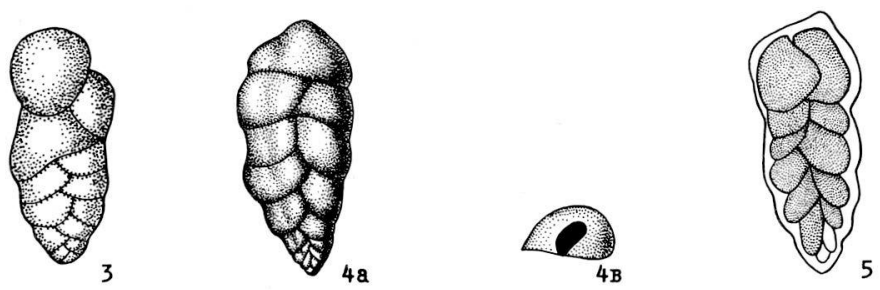

Fig. 3, 4, 5 - Turrilina turcomanica $(x 75), 3,4 a, b-$ the outlook of the test $(4 \mathrm{~b}$ - the view of the aperture), 5 - stained shell in canada balsam.

Test elongated, slightly tapering at the base, broading slowly to the apertural end, rounded in cross section, triserial in the initial part, later biserial; chambers slightly inflated; sutures flush with the surface; wall rather thick, glass like; aperture - loop-shaped opening at the base of convex septal face.

Holotype - slide N 38(38)-61939, length - $0.35 \mathrm{~mm}$, thickness - $0.15 \mathrm{~mm}$.

Remark. Morphological characters of the genus Turrilina were not perfectly investigated. We refer our shells to this genus on the basis of triserial initial part of the test. The lack of material does not permit us to describe them as a new genus.

T. turcomanica differs from the similar species T. pupoides (Nyiro) by slightly broadened upper part of the test and small size.

Distribution: the well Bakhardok, at a depth $20 \mathrm{~m}$, on the sand ground, 3 specimens.

Genus Bolivina d'Orbigny.

Bolivina brodskyi Mikhalevich sp. n. (fig. 6-12).

Test elongate, slightly broading from the base toward the apertural end, rounded at the base, oval in cross section, periferal margin rounded, slightly lobulated; chambers broad, height, slightly convex; sutures thin, slightly deepened and oblique; wall thin; aperture - small opening at the base of the septal face.

Holotype - slide N 41(41)-61942, length - $0.20 \mathrm{~mm}$, thickness - $0.12 \mathrm{~mm}$.

Remark. The species is named in honour of A. L. Brodsky. Perhaps the sh:lls with regular rounded-pored wall described by Brodsky (1928, p. 16, fig. 9) as Textularia belong to this species, as such regular round pores are unknown in Textularia. B. brodskyi differs from the similar species B. simplex Parker with higher chambers and broader base of the test.

Distribution: in the wells Bachardok (at a depth $20 \mathrm{~m}$ ), Mayramiloy (at a depth $80 \mathrm{~m}$ ), Bugdali (at a depth $7 \mathrm{~m}$ ), Mauli (at a depth $16 \mathrm{~m}$ ), on the sand ground, 9 specimens. 

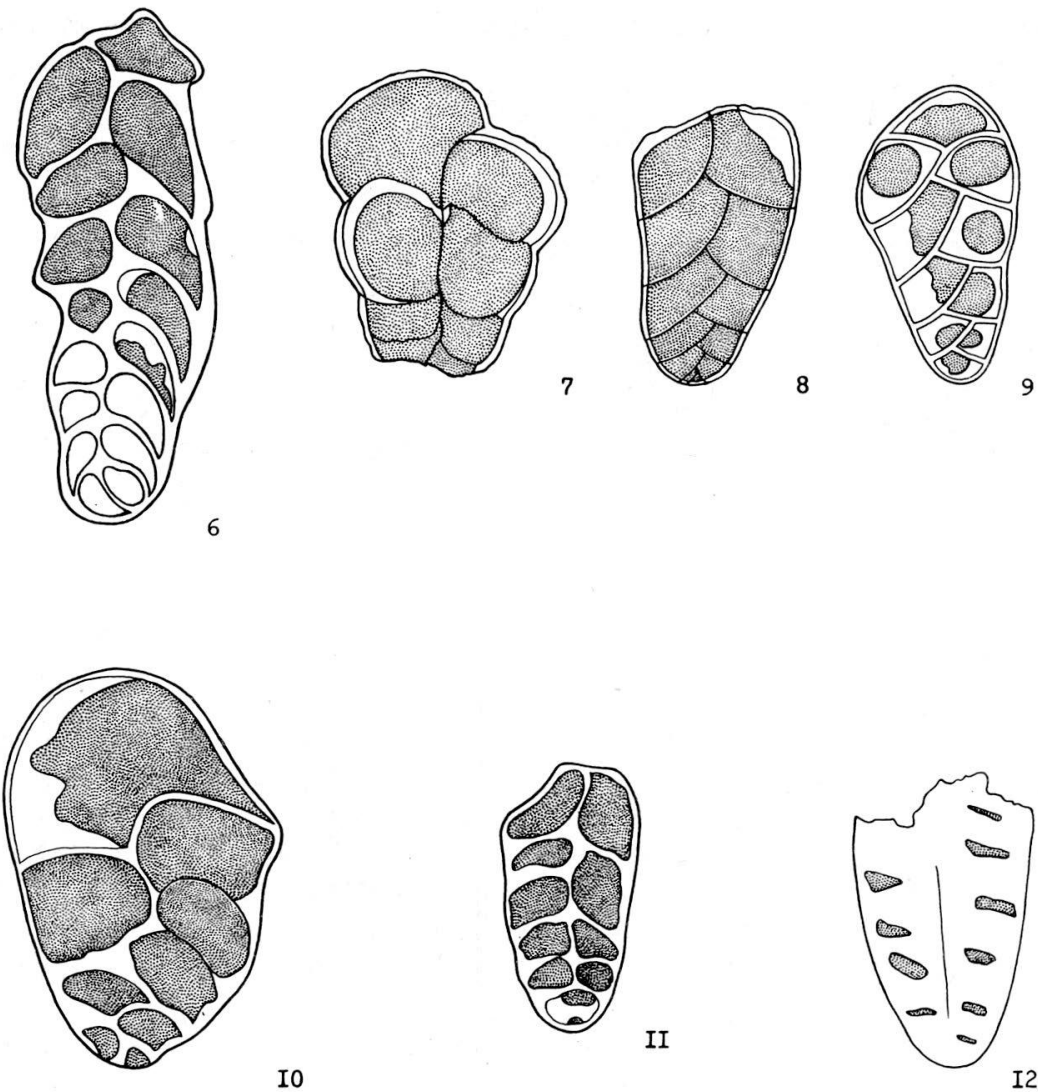

Fig. 6, 7, 8, 9, 10, 11, 12 - Bolivina brodskyi (x75), stained shells in canada balsam.

Family Discorbidae Ehrenberg, 1838. Genus Discorbis Lamarck, 1804. Discorbis subterranea Mikhalevich sp.n. (fig. 13-15).

Test small, unequally biconvex, with low conical spiral side and slightly convex umbilical side, the umbilicus narrow, slightly deepened; the peripheral margin narrowly rounded, slightly lobulated; chambers broad, flat, 5 in a whorl; sutures thin, on the spiral side flush with the surface, slightly curved, on the umbilical side slightly deepened, nearly straight; wall thin, smooth, transparent; aperture - a narrow slit at the base of the septal face of the last formed chamber. 


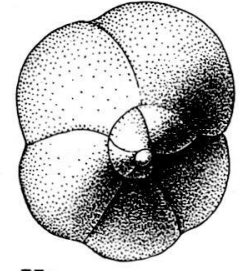

I3a

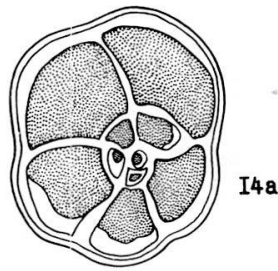

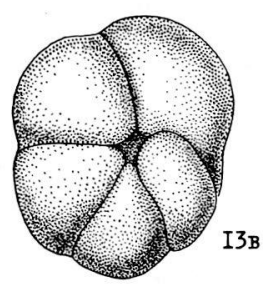

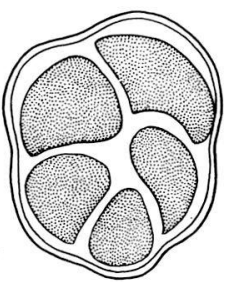

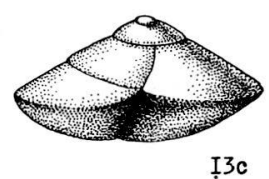

$\mathrm{I} 4 \mathrm{~B}$

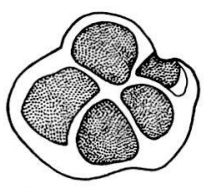

I5

Fig. 13, 14, 15 - Discorbis subterranea (x75), 13 - the outlook of the test, 14, 15 - stained shells in canada balsam, 13a, 14a - the view from the spiral side, 13b, 14b, 15 - the view from the umbilical side, $13 \mathrm{c}$ - peripheral view.

Holotype - slide N 39(39)-61940, diameter - $0.10 \mathrm{~mm}$, thickness - $0.05 \mathrm{~mm}$.

Remarks. D. subterranea differs from D. vilardeboana (d'Orbigny) in having an extremely small test, more convex umbilical side and with the character of the sutures on the umbilical side.

Distribution: in the wells Bakhardok (at a depth $20 \mathrm{~m}$ ), Mayramiloy (at a depth $80 \mathrm{~m}$ ), Kafigshem (at a depth $5 \mathrm{~m}$ ), on the sand ground, 3 specimens.

Family Elphidiidae Galloway, 1933. Genus Elphidium Montfort, 1808.

Elphidium sp. (fig. 16).

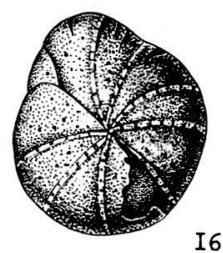

Fig. 16 - Elphidium sp. (x75), the outlook of the test with the remains of stained cytoplasma.

Test oval, equally biconvex, periferal margin narrowly rounded, umbilicus narrow, umbilical area convex; 9 flat triangular chambers in the last whorl; sutures thin, limbate, flush with the surface, with thin short retral processes, about 12 in a row; wall glassy; aperture indistinct.

Diameter $-0.28 \mathrm{~mm}$, thickness $-0.13 \mathrm{~mm}$. 
Remark. The lack of material does not permit me to describe the new species.

Distribution: in the well Bakhardok, at a depth $20 \mathrm{~m}$, on the sand ground, I badly preserved specimen occurred.

Genus Elphidiella Cushman, 1936. Elphidiella sp. (fig. 17, 18, 19).
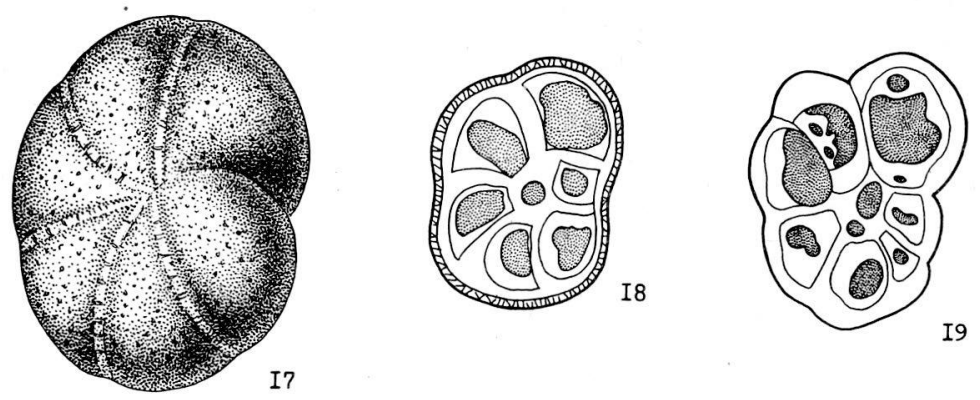

Fig. 17, 18, 19 - Elphidiella sp. (x75), 17 - the outlook of the test, 18, 19 - stained shells in canada balsam.

Test small, oval, thick, laterally compressed, peripheral margin widely rounded, slightly lobulated, umbilicus slightly deepened; chambers slightly convex, broadly triangular, 6-7 in the last whorl; sutures thin, slightly depressed, arched, with thin indistinct transverse marks; wall thin, transparent; external aperture indistinct.

Diameter - $0.17 \mathrm{~mm}$, thickness $-0.05 \mathrm{~mm}$.

Remarks. The shells are similar in the outlook to E. brotzkajae Mayer, inhabiting the Aral and Caspian seas and the Issyk-Kul lake; but in canada balsam the external structure of the sutures looks somewhat different than in dried shells. Therefore we shall not yet refer them to this species.

Distribution:in the wells Mayramiloy (at a depth $80 \mathrm{~m}$ ), Bugdali (at a depth $7 \mathrm{~m}$ ), Mauli (at a depth $16 \mathrm{~m}$ ), on the sand ground, 5 specimens.

Family Cibicididae Cushman, 1927. Genus Cibicides Montfort, 1808.

Cibicides strelkovi Mikhalevich sp. n. (fig. 20-25).

Test small, broadly oval, flat on the spiral side, on the umbilical side convex, not high, softly rounded; peripheral margin slightly lobulated at the end of the whorl, umbilicus narrow, slightly, if at all depressed; chambers rather thin, 6-8 in the last whorl; sutures slightly curved, thin, flush with the surface on the spiral side, slightly deepened on the umbilical side; wall thin; aperture - a thin slit at the base of the septal face.

Holotype - slide N 40(40)-61941, diameter - $0.15 \mathrm{~mm}$, thickness - $0.05 \mathrm{~mm}$.

Remarks. C. strelkovi resembles $C$. io Cushman, but differs from this species and from all the other species of the genus in being extremely small.

Distribution: in the wells Bessyk-Ty (at a depth $5 \mathrm{~m}$ ), Tyu-Sup-Berdy (at a 


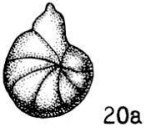

$20 \mathrm{a}$

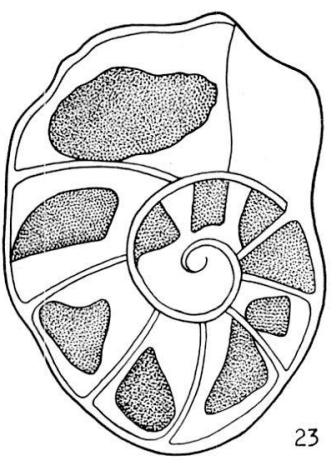

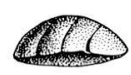

$20 \mathrm{~B}$

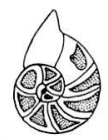

2I
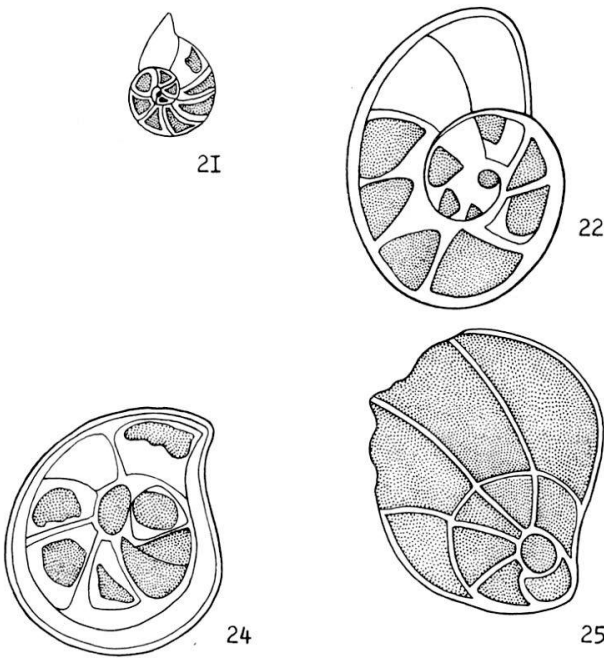

25

Fig. 20, 21, 22, 23, 24, 25 - Cibicides strelkovi, 20, $21-(\mathrm{x} 34), 22-25-(\mathrm{x} 75)$; 20a - the view from the umbilical side, $20 \mathrm{~b}$ - peripheral view, 21-25 - stained shells in canada balsam, views from the umbilical side.

depth $30 \mathrm{~m}$ ), Mayramiloy (at a depth $80 \mathrm{~m}$ ), Bugdali (at a depth $7 \mathrm{~m}$ ), Yerbent (at a depth $30 \mathrm{~m}$ ), Bachardok (at a depth $20 \mathrm{~m}$ ), Mauli (at a depth $16 \mathrm{~m}$ ), on the sand ground, 12 specimens.

Every new fact of the discoveries of foraminifera in underground waters shows us that their presence is not occasional and confirms the supposition of the presence of an original, apparently very ancient foraminiferal fauna living in the underground waters of heightened salinity. This fauna is a part of the underground fauna called by Nalivkin (1965) "the planetar fauna of the new type".

Analyzing the distribution of the foraminiferal fauna in the ground waters, its connection with the region of bedding of those waters only in the zone of the balance of runoff and evaporation was found, where the salinity degree and the salinity composition of well water approaches the salinity of the Aral, Caspian and Black seas. At the same time the foraminifera were not found in the region of distribution of fresh subsoil waters (map 1).

The composition of the foraminiferal fauna of the underground waters is close to the fauna of coastal shallow brakish and much fresher sea parts (lagoons, estuaries) in the tropical and subtropical zones of the World Ocean, where many representatives of the genera Haplophragmoides, Jadammina, Elphidiella and Elphidium, Discorbis, Bolivina and representatives of the 
family Miliolidae occur. Close family connections: the presence of morphologically similar and even common species connote the fauna of the underground waters and the fauna of the continental seas of Middle Asia (e.g. Birsteiniolla macrostoma is discovered in the underground water of the cave Kaptar-Hana, in the Issyk-Kul lake and in the Aral and Caspian seas). Such similarity confirms the hypothesis of Brodsky on the transition of the coastal lagoon fauna into the interstitial coast environment after the sea regression. This is supported by Birstein and Ljovuschkin (1965).

However the foraminifera of the continental waters are poorly known. Lack of materials does not permit solving the problem of their migrations, their age and the more accurate definition of the formation and age of the territories, where they exist.

The importance of both theoretical and practical aspects of the problem (the necessity of the accurate identification of recent and fossil forms, discovered in the ground) emphasize the task of further significant investigations in this field.

\section{SUMMARY}

New data obtained during the expedition to Middle Asia (1973) essentially enlarge our knowledge of foraminifera living in underground waters. Seven new species were discovered in the wells of the Kara-Kum and Ust-Urt deserts. All of them contain cytoplasma. The wells are situated in the region of bedding of underground waters of the heightened salinity in the zone of balance of runoff and evaporation.

The majority of the species described in our work like many of the species recorded from the underground waters earlier (Brodsky, 1928; Nikoljuk, 1968; Jankovskaja and Mikhalevich, 1972) belong to the genera living in coastal brackish parts of tropical seas. This fact confirms the supposition of Brodsky about the transition of the marine coastal foraminiferal fauna to underground habitats after the regression of the sea. This fauna is a part of the underground fauna called by Nalivkin (1965) "the planetar fauna of the new type".

\section{RESUME}

Les nouveaux résultats obtenus au cours de l'expédition en Asie (1973) accroissent essentiellement notre connaissance des Foraminifères des eaux souterraines. Sept nouvelles espèces ont été découvertes dans les puits des déserts de Kara-Kum et de Ust-Urt. Tous contenaient du cytoplasme. Les puits sont situés dans la région où s'étend la nappe des eaux souterraines de haute salinité, dans une zone d'équilibre pour l'écoulement et l'évaporation.

La plupart des espèces décrites dans notre travail appartiennent aux genres vivant dans les zones côtières saumâtres des mers tropicales, comme nombre d'espèces signalées auparavant dans les eaux souterraines (Srodsky, 1928; Nikoljuk, 1968; Jankovskaja et Mikhalevich, 1972). Cela confirme l'hypothèse de Brodsky sur le passage de la faune des foraminifères des côtes maritimes à l'habitat souterrain après la transgression marine. Cette faune fait partie de la faune appelée "la faune planétaire de type nouveau" par Nalivkin (1965). 


\section{REFERENCES}

Brodsky A. L. (1928) - Foraminifera (Polythalamia) im Grundwasser der Wüste Kara-Kum. Acta Univ. Asiae Mediae, ser. VIII-a, Zool., fasc. 5:3-16.

Brodsky A. L. (1929) - Fauna vodoemov pustyni Kara-Kum. Ibid., ser. XII, fasc. 5:1-42.

Birstein J. A., S. I. Ljovuschkin (1965) - Faune des eaux souterraines saumâtres de l'Asie Centrale. Int. J. Speleol., v. I, pt. 3:307-320.

Gauthier-Lievre L. (1935) - Sur une des singularités de l'oued Rhir: des Foraminifères Thalassoides vivants dans les eaux sahariennes. Bull. Soc. H.N. Afrique du Nord, XXVI:142147.

Jankovskaja A. I., V. I. Mikhalevich (1972) - Foraminifera of the Issyk-Kul lake and of the underground waters of the Middle Asia. Dokl. AN SSSR, t. 205, N 4:1005-1008.

Mikhalevich V. I. (1971) - Sea Rhizopoda in the Issyk-Kul lake. Mater. I Kongr. of Protozool. Soc. USSR, Baku: 293-294.

Nalivkin D. V. (1965) - Uchenie o facijach. Geographicheskie uslovyja obrasovanyja osadkov. Thes. XI sess. Paleontol. Soc. USSR:1-3.

Nikoljuk V. F. (1968) - Was bergen die Erdschichten der Wüste Kara-Kum? Pedobiologia, 7:335352 .

Rezvoy P. D. (1951) - O nakhozhdenii foraminifer v Bolshom Gulikovskom ozere. Dokl. AN Tadzh. SSR, vyp. 1:43-46.

Schmalhausen O. I. (1950) - Novyi vid foraminifera iz ozera Bolpashsor. Dokl. AN SSSR, t. LXXV, n 6:869-872. 